\title{
The effect of human disturbance on site habitat diversity and avifauna community composition in suburban conservation areas
}

\author{
P. F. Mooney \\ School of Architecture and Landscape Architecture, \\ University of British Columbia, Canada
}

\begin{abstract}
This study evaluated the causes and effects of habitat heterogeneity in suburban conservation areas of the metropolitan Vancouver area. Site disturbance, soil conditions and plant associations were evaluated for their relationship to habitat heterogeneity. Habitat heterogeneity was correlated with breeding bird populations and the type of birds found.

Three, urban conservation sites were surveyed for site conditions and avian populations. Data were spatially referenced in a geographic information system (GIS) and a habitat diversity index rating was calculated for each site. Site habitat diversity ratings were compared with the avian species richness and the birds recorded were classified as urban exploiters, adapters or avoiders.

It was found that human disturbance and biotic succession had produced a mosaic of seral stage plant communities that increased habitat heterogeneity. Site-level habitat heterogeneity was correlated with avian species richness. All categories of urban and non-urban birds were recorded.

Suburban conservation areas can support high avian species richness, including urban avoiders. Site-level habitat heterogeneity and avian species richness are strongly correlated. These findings can assist in selecting and managing urban conservation sites to maintain regional biodiversity.

Keywords: urban biodiversity, site-level habitat diversity, habitat diversity index, urban exploiters, urban adapters, urban avoiders, conservation.
\end{abstract}

\section{Introduction}

The extensive and intensive alteration of land cover associated with urbanization negatively impacts biodiversity in urban regions [1] with more biodiverse 
regions being at greater risk for biodiversity loss [2]. In most urban regions, nonnative species abound, habitats are fragmented, habitat quality is poor and species migrations are disrupted, leading to high rates of local extinctions $[2,3]$.

While these regional impacts of urbanization are well established, the causes of local land cover change, its impacts and the appropriate measures to support site-level biodiversity are less well understood. This study evaluated human disturbance as a cause of habitat diversity (or heterogeneity) and the effects of habitat heterogeneity on avian species richness and avifauna community composition, in suburban conservation areas, in order to better manage such sites to support regional biodiversity.

These findings can assist in selecting and managing urban conservation sites to maintain regional biodiversity.

Despite the negative effects of urbanization, many cities were founded in biologically diverse eco regions that still support significant species richness and remnant populations of uncommon species $[4,5]$. Such regions may play crucial roles in supporting regional and even hemispheric biodiversity [2, 4, 6]. Preserving the remaining biodiversity in urban regions will require conservation actions that are informed by direct local knowledge [7-9].

\section{Habitat heterogeneity and species richness}

Habitat heterogeneity is a measure of the diversity and evenness of variation in land cover. It has been consistently correlated with avian diversity [10-16].

Studies of patch level avian habitat have typically used point source data of structural or floristic diversity as measures of both habitat diversity and quality. However, habitat diversity is dependent, in part, on the scale of observation and must be measured at the corresponding landscape scale [17]. This study used a site habitat diversity index (HDI) to measure the effect of habitat heterogeneity on avian species richness. The HDI is a more suitable measure of site level diversity than point source data, since it incorporates the variation among all habitats on a site and not just the diversity within individual vegetation patches.

Human disturbances, such as industrial activity, clearing and filling are intrinsic to cities. When sites are abandoned after disturbance, biotic succession follows. Grasses and herbaceous plants colonize the bare soil, followed by pioneer woody plants [18]. Small patches of incremental disturbance and subsequent plant succession within a site result in the development of a shifting mosaic of different seral stage plant communities.

Diverse plant associations may also develop in response to variation in environmental gradients such as soil moisture, fertility and $\mathrm{pH}$ [19-21]. Thus, the plant associations found on any site may result from biotic succession in response to site disturbance or the environmental gradients of the site, or a combination of the two.

\section{Urban birds}

Birds that occupy early seral stage landscapes increase in number in suburban environments by taking advantage of the supplemental food and nest sites 
provided by these anthropogenic habitats and are termed urban adapters [22-26]. Urban adapters include edge species, omnivores, ground foragers, corvids, seedeaters and aerial sweepers such as swifts [25, 27]. Swallows Tachycineta spp., Bewick's wren Trogolodytes bewickii, red-winged blackbird Agelaius phoeniceus, American robin Turdus migratorius, Anna's hummingbird Calypte anna, American goldfinch Carduelis tristus and chestnut-backed chickadee Parus rufescens are representative species [28].

Other birds have been categorized as urban avoiders and urban exploiters [27]. Both urban adapters and urban exploiters are synanthropic species i.e. species associated with humans [24, 26] while urban avoiders are considered to be non-synanthropic. Urban exploiters include cliff dwellers, cavity nesters, ground foraging seedeaters and omnivores [25]. Peregrine falcons Falco peregrinus, house sparrows Passer domesticus, European starlings Sturnus vulgaris and European rock doves Columba livia are urban exploiters and may be found in the downtown cores of many cities [25, 27]. Urban avoiders include interior nesting birds, tree foraging insectivores, neotropical migrants, and ground nesting birds [25, 27]. Representative species include western wood pewee Contopus sordidulus and Hutton's vireo Vireo huttoni [27]. Research has shown that urban exploiters, adapters and avoiders are non-randomly assembled in urban environments [25].

The designation of bird species as urban exploiters, adapters and avoiders is incomplete. Not all birds have been categorized; some authorities differ as to the appropriate category for a species and some species may behave differently in different regions. For example, Blair [27] considered Steller's jay Cyanocitta californica to be non-synanthropic, while Donnelly and Marzluff [26] considered it to be a synanthropic species. Because it is frequently found at residential bird feeders in this region it was considered to be an urban adapter in this study.

These differences in classification may result from the fact that there is a continuum from true urban avoiders that never venture into urban realms to adaptive-avoiders that make minimal use of urban/suburban habitats [26, 29]. Since the study sites were suburban, it would be expected that urban adapters and exploiters would be numerous while urban avoiders would be absent or minimally present.

\section{Methods}

Three urban conservation areas were selected for study because their similarities maximized control of both site conditions and offsite factors. As well as similar size, location and vegetation, the three sites shared a history of industrial use, abandonment, biotic succession and subsequent protected status. Each site contained a combination of ruderal vegetation, remnant islands of natural vegetation and some managed vegetation. The sites were in coastal locations and had protected status. Two were municipal parks and the third was a designated wildlife management area. All three sites were surrounded by suburban residential communities, with second growth conifer forest on the inland side (see figure 1). 


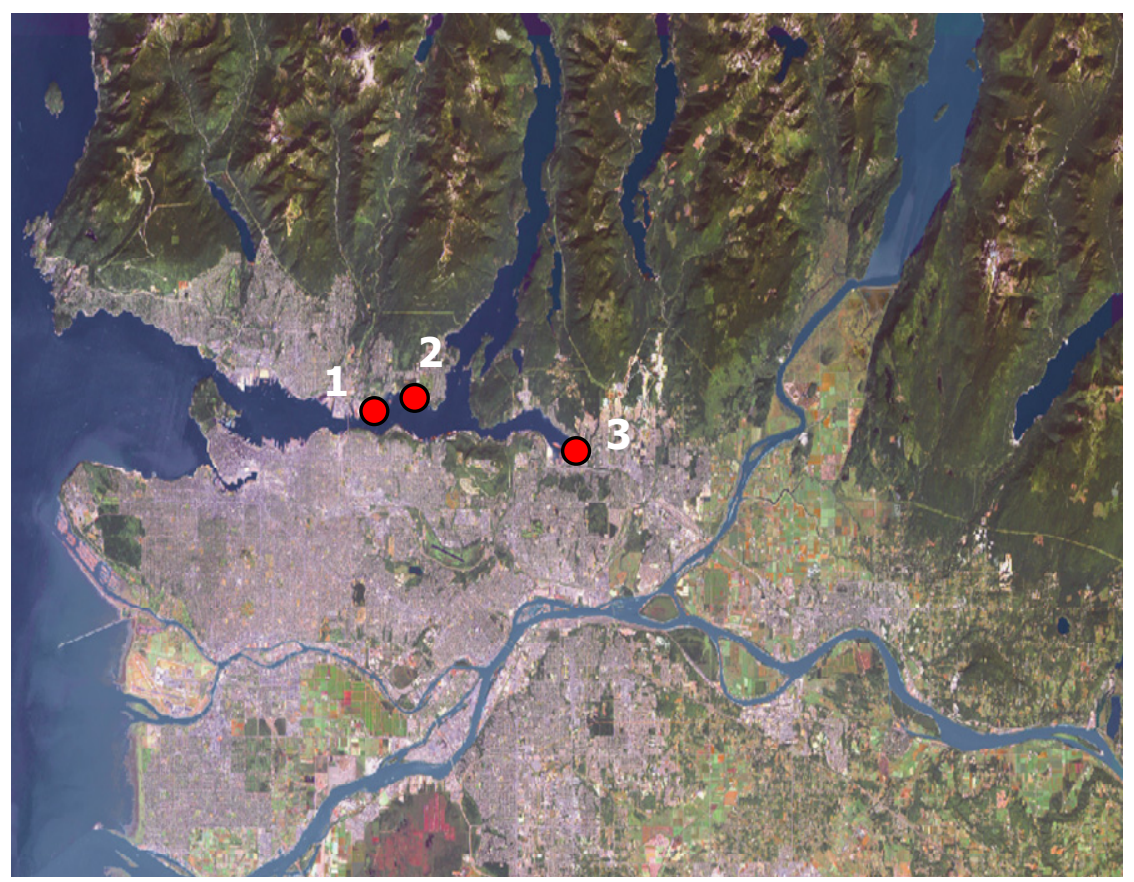

Figure 1: $\quad$ Location of research sites in the metropolitan Vancouver area.

\section{Site inventories}

Inventories of site disturbance and soil moisture and fertility were conducted to determine the causal factors of the mix of habitat types on each site. Birds were surveyed for species richness and the composition of the avian community.

\subsection{Soil moisture and fertility}

Native indicator plants of coastal British Columbia were used to infer soil nitrogen and moisture gradients. The method developed by Klinka et al. [30] uses native plants of coastal British Columbia to indicate site climate and a site's soil moisture and nitrogen gradients. In this classification system, soil nutrient regimes range from very poor to very rich and each plant species indicates a gradient of nutrient and moisture levels.

\subsection{Vegetation surveys}

Aerial photo analysis was used to identify vegetation association patches. This was followed by field surveys to establish patch boundaries and quadrat inventories that recorded the plant associations of each patch on each site. The plant associations of each vegetation patch were converted to habitat types, digitally mapped using GIS Arcview and the area of each habitat patch determined. 


\subsection{Bird surveys}

Birds were surveyed using line transects of each habitat patch on each of the three sites. Surveys were conducted in the early mornings of four consecutive days between mid-May and mid-June. Only birds that were foraging or singing from perches were recorded. Territory mapping was used to transform multiple sightings into breeding territories [31]. All birds were classified as urban adapters, exploiters or avoiders. Those birds that fit the criteria of urban avoider but that nevertheless were recorded on the suburban conservation areas in this study were labeled adaptive-avoiders.

\subsection{Time since disturbance}

Since taking tree core samples was not an option on these public sites, an aerial photo analysis was used to determine the age of each vegetation patch on each site. Stereoscopic aerial photos of the study sites were obtained for the period 1926 to 1999. (After 1999, all the study sites were protected and no new disturbances occurred.) Aerial photography was conducted approximately every 7 years during the period 1926-1999.

The aerial photo analysis showed major disturbances, i.e. site clearing or filling that substantially altered the vegetative community of a patch (see Figure 2). The date of the survey showing the last major disturbance for each

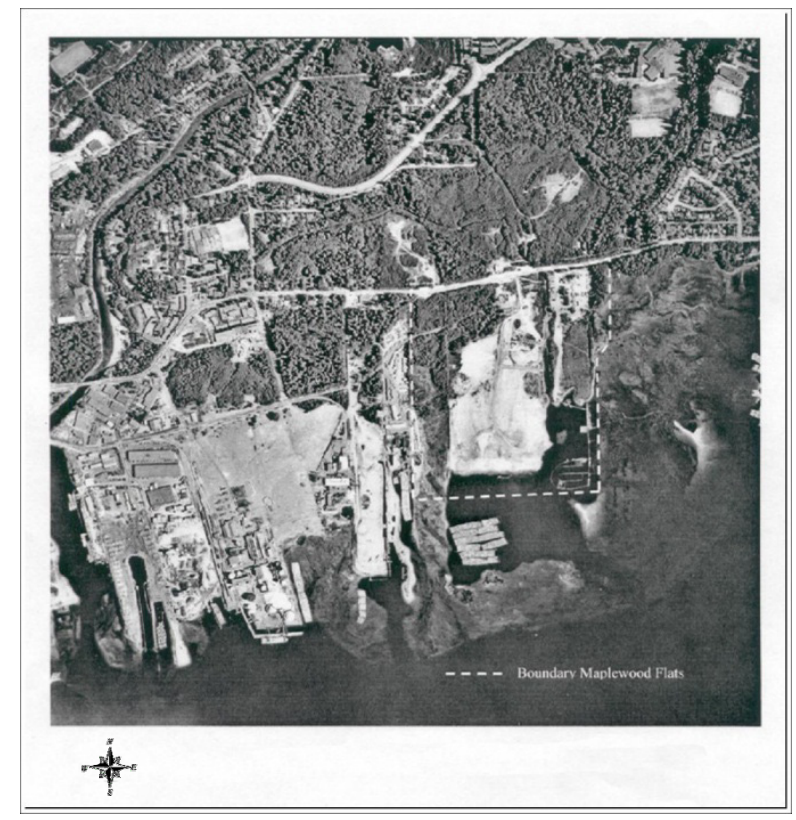

Figure 2: $\quad$ Site 2: Maplewood Flats 1979, showing the extent of disturbance due to extensive filling. 
polygon was subtracted from 1999 to calculate the approximate time since disturbance for each patch.

\section{Habitat diversity index}

To establish the relationship between habitat heterogeneity and avian species richness on the study sites, it was necessary to first measure the habitat heterogeneity of each site. Table 1 was constructed using the habitat maps that had been developed from the vegetative inventories.

Table 1: Habitat areas and percent of site area across all study sites.

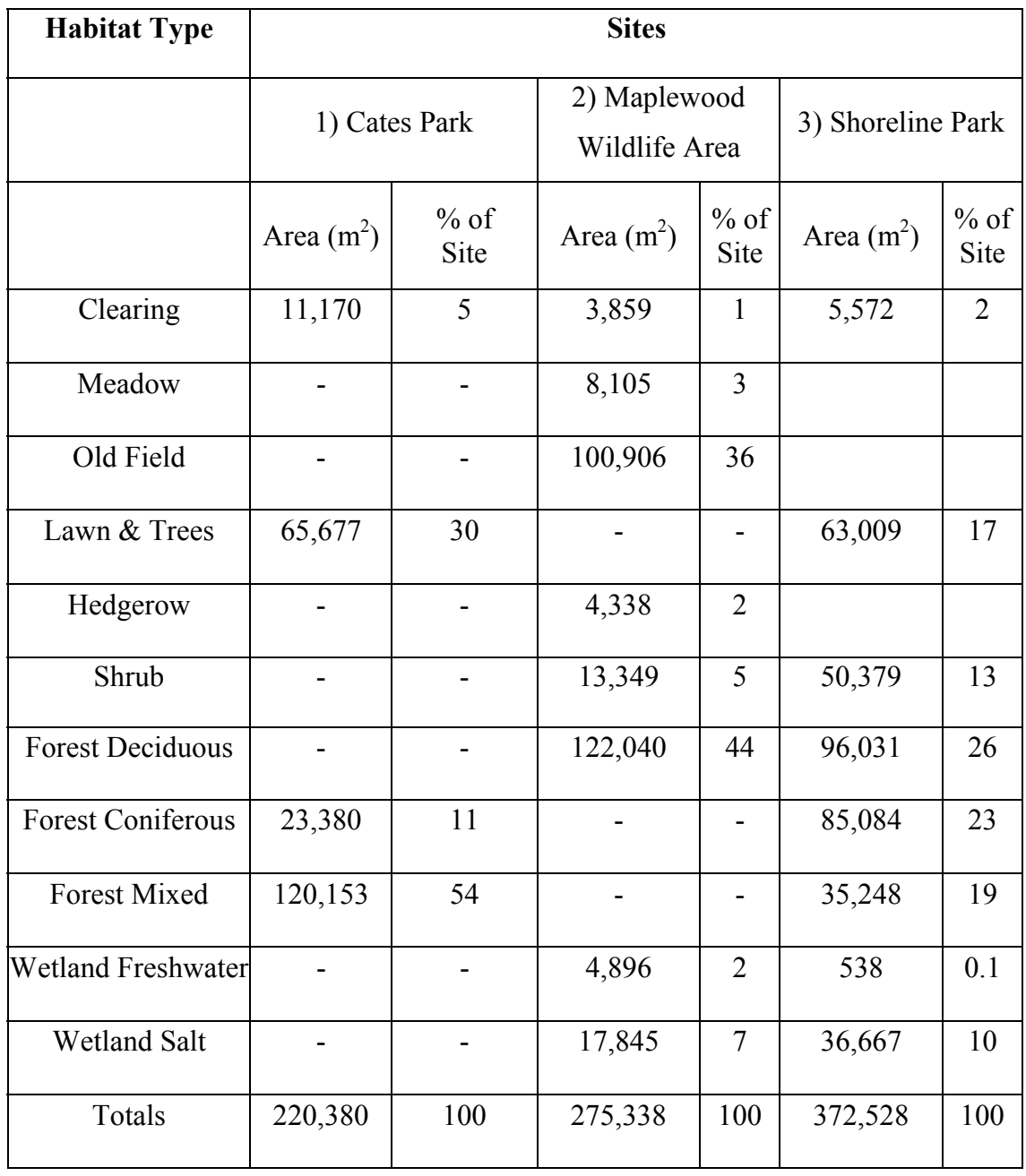


A habitat diversity index (HDI) was calculated for each site using the Simpson's reciprocal diversity index. Simpson's diversity index is often used in ecology to quantify the diversity of a habitat [32]. It measures both the richness or number of species per sample and the evenness or relative abundance of different species in the sample.

Simpson's Index (D) is calculated as:

$$
\mathrm{D}=\frac{\sum \mathrm{n}(\mathrm{n}-1)}{\mathrm{N}(\mathrm{N}-1)}
$$

where $n=$ the total number of organisms of a particular species and $N=$ total number of organisms of all species. In this study, $\mathrm{N}=$ total number of habitats within a site, $\mathrm{n}=$ percent area of each habitat type within a site. Used in this way an index of 0 equals infinite diversity and $1=$ no diversity. Because this is counter-intuitive, the Simpson's reciprocal index (1/D) was used. For the Simpson's reciprocal index, (1/D), the higher the number the greater the diversity. The HDI rating for each site was then compared to the number of bird species using the site.

\section{Results}

\subsection{Soils}

All sites were found to be relatively fertile and different habitat types shared similar moisture and fertility levels. All soils had moisture levels of fresh to very moist, except wetland habitats that were wet to very wet. The soil analysis also revealed that soil fertility did not differ greatly between the study sites or the different habitat types. Of twelve habitat types, eight were rich to very rich and the rest were in the medium to rich categories in terms of soil nutrients. Neither soil fertility nor moisture was found to be a limiting factor to plant growth on the study sites. Moisture levels were high, even in summer, and fertility levels were medium to very rich.

\subsection{Disturbance}

The time since disturbance analysis showed that while the different habitat patches shared similar moisture and fertility levels they differed in age. Patches ranged from a maximum of 50 years to a minimum of 7 years since disturbance.

\subsection{Birds}

Sixty-five bird species recorded on the three study sites. The majority of the bird species found were urban adapters (39) or exploiters (6). This list of synanthropic species included such urban exploiters as European starling, rock dove, and such urban adapters as American goldfinch and northern flicker Colaptes auratus. The 45 synanthropic species comprised 69 percent of the species recorded. This included diving and dabbling waterfowl not usually 
associated with suburban areas but which are common on protected salt water habitats in this region. Twenty species of urban adaptive- avoiders were found on these suburban conservation sites.

\subsection{Habitat diversity and avian species richness}

The HDI ratings for the three sites ranged from $2.5-5.3$. The number of bird species recorded on each site ranged from $28-46$. Figure 3 shows that bird species richness increased with increasing habitat diversity for all three study sites.

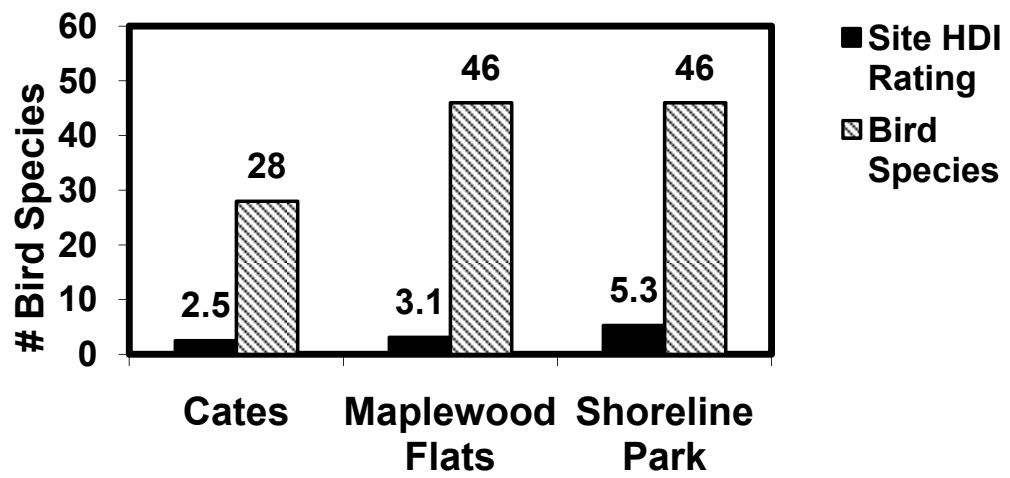

Figure 3: $\quad$ Site habitat diversity index versus bird species richness.

\section{Conclusions}

The key findings may be summarized as follows:

1) Unplanned, incremental, human disturbance and subsequent biotic succession created the mosaic of multiple seral stages found on each of these sites.

2) The seral stages function as multiple habitats creating the HDI measurements recorded.

3) As HDI increases, avian species richness also increases.

4) Many bird species that had been classified as urban avoiders were found to use these suburban, disturbed conservation areas.

\section{Discussion}

\subsection{Habitat heterogeneity and its interactions}

In forest ecosystems in this region, multiple seral stages increase site level habitat heterogeneity and forests having a greater diversity of vegetative composition have greater avian species richness [33]. 
The number of bird species within a habitat patch has been found to increase as the patch size increases. For example, a broadly based study of species/area relations in the United Kingdom and Scandinavia found that bird species richness in 15 hectare woods generally approached a doubling of those found in 1 hectare woods [34]. However within fragments of equal size, those fragments that are more heterogeneous will tend to support a greater number and variety of species than those which are more homogeneous. This may be because heterogeneous habitat fragments are less susceptible to local extinction than more homogeneous habitats [35].

Most studies of urban adapters have looked at the matrix of the suburban landscape $[26,27,36]$. This study found that suburban parks and conservation areas are special patches within the suburban landscape matrix that have higher and different habitat values than the general matrix. Proportionately larger numbers of birds that are considered to be urban avoiders used these habitats ( $31 \%$ of all birds recorded). The urban avoiders recorded in this study were comprised of interior nesting birds such as pileated woodpeckers Dryocopus pileatus, neotropical migrants like Hutton's vireos, western tanagers Piranga ludoviciana and Wilson's warblers Wilsonia pusilla and shorebirds such as solitary and spotted sandpipers Tringa solitari and Actitis macularia. Habitat heterogeneity was found to support increased avian species richness for edge, synanthropic species and also for non-synanthropic urban avoiders. This suggests that in suburban parks and conservation areas, where there are often limited opportunities to increase the size of habitat, increasing the HDI may be a useful tool to increase site level avian diversity and support so called urban avoiders.

In assessing the relationship between avian species richness and landscape attributes, it is necessary to consider both the local and the regional landscape $[35,36]$. The effect of local habitat heterogeneity is moderated by other ecological factors such as habitat area, quality, isolation, and the landscape matrix surrounding the habitat patch. These and other factors are simultaneously functioning to determine bird species distribution in the landscape mosaic [3740].

In the Metro Vancouver region, significant areas of second growth forest are protected as watersheds that provide the regional drinking water. These large patches of intact conifer forest provide habitat for urban avoider species and likely contributed to their presence on the nearby suburban study sites.

\subsection{Site trajectory}

As the study sites are parks and conservation areas, they are now protected from the kind of small scale, intermittent disturbance that led to their present condition. In the absence of active management, these sites will, through succession, develop a more uniform plant community. This will result in a reduction of the site habitat diversity rating with attendant reductions in the numbers of vertebrate species. 


\subsection{Role of disturbance}

Within the three study sites the same disturbance that created mixed seral stages has allowed the introduction and spread of invasive plant species. The most widespread of these is Himalayan blackberry, Rubus discolor. This plant has important habitat value; it provides thicket cover for various sparrows, especially fox and song sparrows, passerella iliaca and melospiza melodia. The berries are eaten copiously by many birds and by black bears, ursus americanus and the plant is a nectar source for several butterflies. Another invasive alien plant, Japanese knotweed, Polyganum cuspidatum is becoming increasingly widespread on the three study sites. These invasive alien plants alter the local biotic community directly through their presence and indirectly through such responses as niche displacement and species evolution in response to the invader [41]. Over time we may expect that the negative effects of invasive plants will increase unless effective control programs are introduced. We would expect blackberry to become a smaller component of the sites as it is shade intolerant and will die out under the forest canopy [42]. The knotweed will continue to spread and, if left unchecked, will in time form a monoculture on the forest floor.

Local land cover, invasive plant species, disturbance, the cessation of disturbance and other unseen forces such as climate change and habitat loss elsewhere will affect the levels of biodiversity found on such suburban sites. These influences are happening now and will continue to effect change. It is expected that climate change will contribute to the spread of invasive species and decline in the populations of native species.

\subsection{Implications for conservation}

These findings have implications for the selection and management of conservation sites in urban ecosystems. In selecting new conservation areas, sites that contained multiple seral stage plant communities and that had high HDI ratings would be preferred over sites having lower HDI ratings, if the conservation goal was to maximize general avian diversity in the urban region.

In managing suburban conservation sites like those in this study, human energy inputs in the form of controlled disturbance or ecological restoration could be used to increase their HDI rating and control invasive plants. This might mean periodically thinning the woody plants in an old field habitat, removing invasive plants or restoring a degraded wetland. The study has shown that past, unplanned human disturbance has inadvertently increased habitat diversity and species richness. It has also demonstrated that high avian diversity values can be found on such sites. Intentional interventions that increase habitat heterogeneity can now be used to increase site habitat diversity indices and enhance site level avian diversity in suburban conservation areas.

If we are to maintain global biodiversity, the global application of ecosystem management and restoration will be required [43]. Within regional conservation agencies, there exists a great need to develop and institutionalize adaptive ecosystem management based on the scientific understanding of local human ecosystems, rather than simply setting land aside in conservation/recreation. 


\section{References}

[1] Lutz, W., Sanderson, W.C. \& Scherbov, S., (eds).The End of World Population Growth in the 21st Century: New Challenges for Human Capital Formation and Sustainable Development, Earthscan: London and Sterling VA, pp. 341, 2004.

[2] Connor, E.F., Hafernik, J., Levy, J., Moore, V.L. \& Rickman, J.K., Insect conservation in an urban biodiversity hotspot. Journal of Insect Conservation, 6 (4), pp. 247-259, 2002.

[3] Marzluff, J.M., Worldwide urbanization and its effects on birds (Chapter 2). Avian Ecology in an Urbanizing World, eds. J.M. Marzluff, R. Bowman \& R. Donnelly, Kluwer Academic Publishers: Boston, pp. 19-48, 2001.

[4] Ricketts, T. \& Imhoff, M., Biodiversity, urban areas, and agriculture: locating priority ecoregions for conservation. Conservation Ecology, 8(2), pp. 1, 2003.

[5] UK Biodiversity Action Plan (UK BAP). Online. http://www.ukbap.org.uk/.

[6] Butler, R.W. \& Campbell, R.W., Birds of the Fraser River Delta: Populations, Ecology, and International Significance, Canada Wildlife Service Occasional Paper: Delta, BC, 65, 1987.

[7] Cook, E.A., Ecological Networks in Urban Landscapes, Wageningen University: Wageningen, The Netherlands, pp. 201, 2000.

[8] Cowling, R.M., Pressey, R.L., Roget, M. \&Lombard, A.T., A conservation plan for a global biodiversity hotspot-the Cape Floristic Region South Africa. Biological Conservation, 112(1-2), pp. 191-216, 2003.

[9] Alberti, M., The effects of urban patterns on ecosystem function. International Regional Science Review, 28(2), pp. 168-192, 2005.

[10] James, F.C., Ordinations of habitat relationships among breeding birds. The Wilson Bulletin, 83, pp. 215-236, 1971.

[11] Wiens, J.A. \& Rotenberry, J.T., Habitat associations and community structure of birds in shrubsteppe environments. Ecological Monographs, 51(1), pp. 21-42, 1981.

[12] Forman, R.T.T. \& Godron, M., Landscape Ecology, John Wiley and Sons: New York, pp. 619, 1986.

[13] Boecklen, W.J., Effects of habitat heterogeneity on the species-area relationships of forest birds. Journal of Biogeography, 13(1), pp. 59-68, 1986.

[14] Bohning-Gaese, K., Determinants of avian species richness at different spatial scales. Journal of Biogeography,24(1), pp. 49-60, 1997.

[15] Kruger, O. \& Lindstrom, J., Habitat heterogeneity affects population growth in goshawk Accipiter gentiles. The Journal of Animal Ecology,70 (2), pp. 173-181, 2001.

[16] Tews, J., Brose, U., Grimm, V., Tielborger, K., Wichmann, M.C., Schwager, M. \& Jeltsch, F., Animal species diversity driven by habitat heterogeneity/diversity: the importance of keystone structures. Journal of Biogeography, 31(1), pp. 79-92, 2004. 
[17] Bissonette, J.A. \& Storch, I., Fragmentation is the message clear? Conservation Ecology 6(2), pp. 14, 2002.

[18] Kimmins, J., Forest Ecology: a Foundation for Sustainable Forest Management and Environmental Ethics in Forestry, Pearson Prentice Hall: New Jersey, pp. 531, 2004.

[19] Whittaker, R.H., Gradient analysis of vegetation. Biological Reviews, 42 (2), pp. 207-264, 1967.

[20] Austin, M.P., Searching for a model for use in vegetation analysis. Plant Ecology, 42, pp. 11-21, 1980.

[21] Partel, M., Local plant diversity patterns and evolutionary history at the regional scale. Ecology, 83(9), pp. 2361-2366, 2002.

[22] Blair, R.B. \& Launer, A.E., Butterfly diversity and human land use: Species assemblages along an urban gradient. Biological Conservation, 80, pp. $113-$ 125, 1997.

[23] Blair, R., Birds and butterflies along urban gradients in two ecoregions of the U.S. (Chapter 3). Biotic Homogenization, eds. J.L. Lockwood \& M.L. McKinney, Kluwer Academic/Plenum Publishers: New York, pp. 33-56, 2001.

[24] Johnston, R.F., Synanthropic birds of North America (Chapter 3). Avian Ecology in an Urbanizing World, eds. J.M. Marzluff, R. Bowman \& R. Donnelly, Kluwer Academic Publishers: Boston, pp. 49-67, 2001.

[25] McKinney, M.L., Urbanization biodiversity and conservation. BioScience, 52, pp. 883-890, 2002.

[26] Donnelly, R. \& Marzluff, J.M., Relative importance of habitat quality, structure and spatial pattern to birds in urbanizing environments. Urban Ecosystems, 9, pp. 99 -117, 2006.

[27] Blair, R., Land use and avian species diversity along an urban gradient. Ecological Applications, 6(2), pp. 506-519, 1996.

[28] Marzluff, J.M., Island biogeography for an urbanizing world: how extinction and colonization may determine biological diversity in humandominated landscapes. Urban Ecosystems, 8, pp. 157-177, 2008.

[29] Schaefer, V. Personal communication, 25 July 2008, Restoration of Natural Systems Program Director, University of Victoria, Victoria, BC

[30] Klinka, K., Krajina, V.J., Ceska, A. \& Scagel, A.M., Indicator Plants of Coastal British Columbia, The University of British Columbia Press: Vancouver, pp. 288, 1989.

[31] Bibby, C.J., Burgess, N.D. \& Hill, D.A., Bird Census Techniques, Academic Press: London, 1992.

[32] Offwell Woodland and Wildlife Trust. Simpson's Diversity Index. Online. http://www.countrysideinfo.co.uk/simpsons.htm

[33] Easton, W.E. \& Martin, K., The effect of vegetation management on breeding bird communities in British Columbia. Ecological Applications, 8(4), pp. 1092-1103, 1998.

[34] Hinsley, S.A., Bellamy, P.E., Enoksson, B., Fry, B., Gabrielsen, L., McCollin, D. \& Schotman, A., Geographical and land-use influences on 
bird species richness in small woods in agricultural landscapes. Global Ecology and Biogeography Letters, 7(2), pp. 125-135, 1998.

[35] Collinge, S.K., Ecological consequences of habitat fragmentation: implications for landscape architecture and planning. Landscape and Urban Planning, 35, pp. 59-77, 1996.

[36] Melles, S., Glenn, S. \& Martin, K., Urban bird diversity and landscape complexity: Species-environment associations along a multiscale habitat gradient. Conservation Ecology, 7(1), pp. 5, 2003.

[37] Law, B.S. \& Dickman, C.R., The use of habitat mosaics by terrestrial vertebrate fauna; implications for conservation and management. Biodiversity and Conservation, 7, pp. 323-333, 1998.

[38] Mason, C.F., Woodland area, species turnover and the conservation of bird assemblages in lowland England. Biodiversity and Conservation, 10(4), pp. 495-501, 2001.

[39] Poulsen, R.O., Avian richness and abundance in temperate Danish forests: tree variables important to birds and their conservation. Biodiversity and Conservation, 11(9), pp. 1572-9710, 2002.

[40] Brotons, L., Herrando, S. \&Martin, J.L., Bird assemblages in forest fragments within Mediterranean mosaics created by wild fires. Landscape Ecology, 19, pp. 663-675, 2004.

[41] Mooney, H.A. \& Cleland, E.E., The evolutionary impact of invasive species. Proceedings of the National Academy of Sciences of the United States of America, 98 (10), pp. 5446-5451, 2001.

[42] Hoshovsky, M., Element Stewardship Abstract for Rubusdiscolor (Rubusprocerus) The Nature Conservancy: Virginia, pp. 1-11, 2000.imapinvasives.org/GIST/ESA/esapages/rubarme.html

[43] Nellemann, C. \& Corcoran, E., (eds). Dead Planet Living PlanetBiodiversity and Ecosystem Restoration for Sustainable Development: A rapid Response Assessment, United Nations Environment Programme: United Nations, pp. 112, 2010. 